Thematic course: Kinetics and mechanism of acyl transfer reactions. Part 18.

\title{
Quantum-chemical study of mechanisms of benzamide and benzenesulfonamide reactions with 3 -nitrobenzenesulfonic acid chloride in the gas phase
}

\author{
(C) Ludmila B. Kochetova, Tatyana P. Kustova, ${ }^{*+}$ and Alona A. Kruglyakova \\ Department of Organic and Physical Chemistry. Ivanovo State University. \\ Ermak St., 39. Ivanovo, 153025. Russia.Phone: +7 (84932)37-37-03.E-mail: kustova_t@mail.ru
}

\begin{abstract}
*Supervising author; ${ }^{+}$Corresponding author
Keywords: quantum chemical simulation, reaction mechanism, sulfonylation, benzamide, benzenesulfonamide, 3-nitrobenzenesulfonyl chloride.
\end{abstract}

\begin{abstract}
Quantum-chemical simulation of mechanisms of 3-nitrobenzenesulfonic acid chloride interactions with benzoic and benzenesulfonic acids amides in the gas phase was carried out by calculating the threedimensional potential energy surfaces of these reactions (DFT//B3LYP/6-311G(d,p) level). It was found that in both of the processes considered, a single route can be realized containing a single saddle point and starting as an axial attack of the nucleophile. Further approach of the reagent molecules proceeds with a decrease in the angle of nucleophilic attack to $\approx 130^{\circ}$ in the reaction transition state and $\approx 100^{\circ}$ - in the reaction product sulfonamide. It was shown that the studied reactions proceed according to the bimolecular concerted mechanism of nucleophilic substitution $\mathrm{S}_{N} 2$, which implies the formation of a single transition state along the reaction pathway. It was found that the geometric structure of the reaction centers in the transition states of the processes is intermediate between the trigonal bipyramid and the tetragonal pyramid, which is explained by the change in the angle of nucleophilic attack when the reagent molecules approach each other. It was found that in benzamide sulfonylation reaction, a cyclic transition state is formed, in which the forming and loosening bonds lie in the same plane, and the $\mathrm{H}-\mathrm{Cl}$ distance corresponds to the length of the hydrogen bond. In benzenesulfonamide reaction with 3-nitrobenzenesulfonyl chloride, the transition state is not cyclic. The activation energies of the reactions are calculated; they were $155 \mathrm{~kJ} / \mathrm{mol}$ in the benzamide sulfonylation reaction and $150 \mathrm{~kJ} / \mathrm{mol}$ in the process with the participation of benzenesulfonic acid amide. The closeness of the obtained values is associated with the similar structure of the amide and sulfamide groups containing electrophilic centers near the amino groups. A significant difference in the rate constants of the studied reactions, which was found earlier, when they occur in aqueous dioxane, is explained by the features of $\mathrm{CONH}_{2}$ and $-\mathrm{SO}_{2} \mathrm{NH}_{2}$ groups specific solvation and the contribution of the entropy factor to the reaction rate: the cyclic transition state of the benzamide reaction with 3-nitrobenzenesulfonyl chloride is more ordered in comparison with a non-cyclic transition state of the reaction with benzenesulfonamide participation, which can promote faster occurence of the first process.
\end{abstract}

\section{References}

[1] T.P. Kustova, L.B. Kochetova, and N.V. Kalinina. Reactivity of $\alpha$-alanine in arensulfonylation in aqueous-organic media: kinetic experiment and reaction root simulation. Butlerov Communications. 2011. Vol.27. No.13. P.1-12. ROI: jbc-02/11-27-13-1

[2] N.R. Sokolova, E.V. Nikitina, L.B. Kochetova, N.V. Kalinina, and T.P. Kustova. Kinetics and mechanism of acyl transfer reactions. Part 2. Kinetics of heterocyclic amines arensulfonylation in aqueous 1,4-dioxane. Butlerov Communications. 2012. Vol.29. No.1. P.7-14. ROI: jbc-02/12-29-1-7

[3] L.B. Kochetova, N.V. Kalinina, L.V. Kuritsyn, E.V. Nikitina and T.P. Kustova. The kinetics and mechanism of the acyl transfer. Part 3. Glycine and ammonia reactivity in acyl transfer reactions. Butlerov Communications. 2012. Vol.30. No.6. P.81-88. ROI: jbc-02/12-30-6-81

[4] L.B. Kochetova, M.G. Paikova, N.V.Kalinina, and T.P. Kustova. Kinetics and mechanism of acyl transfer reactions. Part IV. Quantum chemical simulation of the mechanism of benzoyl chloride and benzenesulphonyl chloride interactions with amino compounds of different classes. Butlerov Communications. 2013. Vol.35. No.9. P.1-8. ROI: jbc-02/13-35-9-1 
[5] L.B. Kochetova, N.V. Kalinina, T.P. Kustova, and L.V. Kuritsyn. Kinetics and mechanism of acyl transfer reactions. Part 5. Dipeptides and amino acids reactivity in sulfamide bond formation processes Butlerov Communications. 2013. Vol.36. No.12. P.1-7. ROI: jbc-02/13-35-12-1

[6] L.B.Kochetova, N.V. Kalinina, T.P. Kustova, and L.V. Kuritsyn. Kinetics and mechanism of acyl transfer reactions. Part 6. Quantum chemical interpretation of dipeptides and aminoacids reactivity in processes of acids amides and sulfamides formation. Butlerov Communications. 2013. Vol.36. No.12. P.97-104. ROI: jbc02/13-36-12-97

[7] L.V. Kuritsyn, L.B. Kochetova, N.V. Kalinina, and T.P. Kustova. Kinetics and mechanism of acyl transfer reactions. Part 7. Influence of $\mathrm{pH}$ medium on the reactivity of amines in $\mathrm{N}$-acylation. Butlerov Communications. 2014. Vol.37. No.1. P.33-38. ROI: jbc-02/14-37-1-33

[8] L.B.Kochetova, N.V. Kalinina, L.V. Kuritsyn, and T.P. Kustova. Kinetics and mechanism of acyl transfer reactions. Part 8. Influence of the solvent water-2 propanol composition on the kinetics of alyphatic amines reactions with 4-nitro phenylbenzoate. Butlerov Communications. 2014. Vol.38. No.5. P.39-47. ROI: jbc-02/14-38-5-39

[9] L.B. Kochetova, N.V. Kalinina, L.V.Kuritsyn, and T.P. Kustova. Kinetics and mechanism of acyl transfer reactions. Part 9. Influence of ester structures on kinetics of piperidine and morfoline $N$-acylation in aqueous-organic solvents. Butlerov Communications. 2014. Vol.40. No.11. P.59-66. ROI: jbc-02/1440-11-59

[10] L.B. Kochetova, N.V. Kalinina,Yu.E. Grabchilova, K.A. Simonova, and T.P. Kustova. Kinetics and mechanism of acyl transfer reactions. Part 10.Reactivity of dipeptides and esters of carboxylic acids at their interaction in aqueous dioxane solutions. Butlerov Communications. 2015. Vol.43. No.7. P.1-11. DOI: $10.37952 / R O I-j b c-01 / 15-43-7-1$

[11] L.B.Kochetova, N.V. Kalinina, D.S. Soloviyova, O.Yu. Dicina, L.V. Kuritsyn, and T.P. Kustova. Kinetics and mechanism of acyl transfer reactions. Part 11. $L$-Lysine and $L$-ornitine reactivity in reactions with 4-nitrophenyl acetate and picryl benzoate in aqueous 1,4-dioxane solutions. Butlerov Communications. 2016. Vol.45. No.1. P.145-151. DOI: 10.37952/ROI-jbc-01/16-45-1-145

[12] L.B. Kochetova, T.P. Kustova, L.V.Kuritsyn and O.Y. Dicyna. Kinetics and mechanism of acyl transfer reactions. Part 12. Reactivity of aryl amines in amides formation. Butlerov Communications. 2016. Vol.47. No.9. P.95-105. DOI: 10.37952/ROI-jbc-01/16-47-9-95

[13] L.B. Kochetova, T.P. Kustova, D.E. Troitskaya, and Yu.M. Romanova. Kinetics and mechanism of acyl transfer reactions. Part 13. Quantum chemical simulation of mechanisms of the reactions of secondary fatty aromatic amines arensulfonation. Butlerov Communications. 2017. Vol.51. No.9. P.45-56. DOI: 10.37952/ROI-jbc-01/17-51-9-45

[14] L.B. Kochetova, and T.P. Kustova. Kinetics and mechanism of acyl transfer reactions. Part 14. Aminolysis of esters: kinetic experiment and computer simulation of the mechanism. Butlerov Communications. 2018. Vol.53. No.1. P.33-56. DOI: 10.37952/ROI-jbc-01/18-53-1-33

[15] L.B. Kochetova and T.P. Kustova. Kinetics and mechanism of acyl transfer reactions. Part 15. Quantum chemical simulation of mechanisms of reactions of $N$-ethylaniline sulfonation. Butlerov

Communications. 2019. Vol.57. No.2. P.19-27. DOI: 10.37952/ROI-jbc-01/19-57-2-19

[16] L.B. Kochetova and T.P. Kustova. Kinetics and mechanism of acyl transfer reactions. Part 16. Quantum chemical simulation of mechanism of $N$-methylaniline sulfonation in aqueous 1,4-dioxane. Butlerov Communications. 2020. Vol.61. No.1. P.1-8. DOI: 10.37952/ROI-jbc-01/20-61-1-1

[17] L.B. Kochetova, T.P. Kustova and A.A. Kruglyakova. Kinetics and mechanism of acyl transfer reactions. Part 17. Quantum-chemical study of mechanisms of sulfonation of benzoic and benzeneslfonic acids hydrazides in the gas phase. Butlerov Communications. 2020. Vol.62. No.5. P.107-115. DOI: 10.37952/ROI-jbc-01/20-62-5-107

[18] Kinetika reaktsiy atsyl'nogo perenosa. Kuristyn L.V. [and etc.]; ed. by L.V. Kuristyn. Ivanovo: Ivan. State. University. 2006. 260p. (russian)

[19] Granovsky Alex A., Firefly version 7.1.G. www http://classic.chem.msu.su /gran/firefly/index.html.

[20] T.P. Kustova, A.A. Kruglyakova, L.B. Kochetova. Reactivity of benzamide in sulfonylation. Abstracts of the XII All-Russian School-Conference of Young Scientists "Theoretical and Experimental Chemistry of Liquid-Phase Systems" (Krestovsky Readings). October, 7-11, 2019. Ivanovo. 2019. P.14. (russian)

[21] T.P. Kustova, M.A. Agafonov, A.A. Kruglyakova, and L.B. Kochetova. Reactivity of 2-sulfobenzoic acid imide and benzenesulfonamide in arenesulfonylation. Russian Journal of Organic Chemistry. 2019. Vol.55. No.6. P.891-895. (russian) 